\title{
Identidad rural: discursos e imágenes en pequeñas localidades de Paysandú, Uruguay
}

\section{Identidade rural: discursos e imagens em pequenas localidades de Paysandú, Uruguai}

\section{Rural identity: discourses and images in small localities of Paysandú, Uruguay}

\author{
Gonzalo Vicci ${ }^{1}$ \\ Mónica Cabrera²
}

DOI: http://dx.doi.org/10.20435/serie-estudos.v26i58.1604

\begin{abstract}
Resumen: Este artículo tiene como objetivo exponer las líneas centrales de un proyecto de trabajo que se propone identificar y analizar participativamente el impacto que generan los discursos normalizados en relación a la ruralidad en el entorno de las pequeñas comunidades rurales del interior del departamento de Paysandú, Uruguay. El contexto de generalización de acceso a conexión a Internet y dispositivos de información y comunicación en todo el Uruguay podría ser desencadenante de modificaciones en la forma en la que los niños en edad escolar que residen en el medio rural están construyendo sus identidades. Interesa poner atención en los condensados visuales que circulan, si vienen de lo tradicional o el entorno familiar o descartar el supuesto de hibridación que desencadena la globalización, identificando los mecanismos a través de los cuales se conforman esas identidades de la ruralidad y el vínculo con los espacios comunes del entorno. Se propone tomar como centro las escuelas rurales unidocentes y multigrado, considerando que constituyen y definen un espacio público de construcción de ciudadanía en un territorio específico y seleccionado. Si bien estaba prevista la implementación de este dispositivo, la irrupción de la pandemia frenó la posibilidad de concretar las actividades tal cual se estaban diseñadas, lo cual modificó el proceso y abrió el desafío de explorar nuevas formas de aproximación. Sobre ese proceso da cuenta la presente comunicación.
\end{abstract}

Palabras clave: cultura visual; identidad local; educación rural.

Resumo: O objetivo deste artigo é delinear as linhas principais de um projeto que visa identificar e analisar, de forma participativa, o impacto dos discursos padronizados relacionados com a ruralidade no ambiente das pequenas comunidades rurais do interior do departamento de Paysandú, no Uruguai. O contexto de acesso generalizado à ligação à Internet e aos dispositivos de informação e comunicação em todo o Uruguai poderia ser um desencadeador de mudanças

\footnotetext{
${ }^{1}$ Universidad de la República (UDELAR), Montevideo, Uruguay.

${ }^{2}$ Universidad de la República (UDELAR), Paysandú, Uruguay.
} 
na forma como as crianças em idade escolar que vivem em zonas rurais estão a construir as suas identidades. É interessante prestar atenção aos condensados visuais que circulam, sejam eles provenientes do ambiente tradicional ou do ambiente familiar, ou descartar a hipótese de hibridização que a globalização desencadeia, identificando os mecanismos através dos quais estas identidades de ruralidade e a ligação com os espaços comuns do ambiente são moldadas. Propõe-se centrar-se nas escolas rurais mono e multiprofissionais, considerando que constituem e definem um espaço público para a construção da cidadania num território específico e selecionado. Ainda que a implementação deste dispositivo tivesse sido prevista, o surto da pandemia parou a possibilidade de realizar as atividades tal como foram concebidas, o que modificou o processo e abriu o desafio de explorar novas formas de abordagem. Este documento relata este processo.

Palavras-chave: cultura visual; identidade local; educação rural.

Abstract: The objective of this article is to present the main lines of a work project aimed at identifying and analyzing in a participatory manner the impact generated by standardized discourses related to rurality in the environment of small rural communities in the interior of the department of Paysandú, Uruguay. The context of generalized access to Internet connection and information and communication devices throughout Uruguay could be a trigger for modifications in the way in which school-age children living in rural areas are constructing their identities. It is interesting to pay attention to the visual condensates that circulate, whether they come from the traditional or family environment, or to discard the assumption of hybridization triggered by globalization by identifying the mechanisms through which these identities of rurality and the link with the common spaces of the environment are shaped. It is proposed to focus on rural single-teacher and multigrade schools, considering that they constitute and define a public space for the construction of citizenship in a specific and selected territory. Although the implementation of this device had been foreseen, the outbreak of the pandemic stopped the possibility of carrying out the activities as they were designed, which modified the process and opened the challenge of exploring new ways of approaching it. This paper reports on this process.

Keywords: visual culture; local identity; rural education.

\section{INTRODUCCIÓN}

La dualidad campo-ciudad está presente permanentemente en los discursos políticos, en los medios de comunicación, en la fundamentación de políticas públicas de ordenamiento territorial, descentralización y regionalización nacional, así como en los imaginarios educativos que sustentan a las instituciones del estado encargadas de este tema. Esta dualidad incluye fundamentos productivos, de acceso a los bienes y servicios y también a los productos culturales y la educación. La construcción de la identidad local, diferenciada de otras identidades nacionales, se explica a través de la producción de imágenes, objetos, artefactos y en el marco de un conjunto de prácticas sociales y culturales en un determinado espacio territorial. De ahí que explorar la identidad rural uruguaya desde la perspectiva 
de los Estudios de Cultura Visual, en una época marcada por la relación con las Tecnologías de la Información y la Comunicación (TIC) y en un país con alta cobertura de acceso a Internet es una oportunidad para identificar un conjunto de conclusiones que puedan ser discutidas y apropiadas en distintos espacios.

Paysandú es un departamento del litoral de Uruguay que cuenta con una población de 113.107 habitantes - según datos del Censo 2011- de los cuales cerca de 80.000 habitan la ciudad capital. La permanencia de las familias y sobre todo de los más jóvenes en el medio rural constituye una preocupación social y es una temática abordada desde diferentes instituciones públicas que han procurado proyectos adaptados para fomentar una política de promoción de la permanencia de las familias en el medio rural y en las pequeñas localidades del interior. Esta realidad, seguramente se repita en varios países de Latinoamérica, pero se hace particularmente compleja en la perspectiva de crisis demográfica por la que atraviesa Uruguay desde hace varios años. Esto resulta paradójicamente, además, ya que sucesivos gobiernos han señalado al campo (a través de políticas concretas de producción y exportación) como un espacio donde depositar las bases del desarrollo económico del país a través del impulso agropecuario orientado, fundamentalmente, a la ganadería extensiva, la forestación e instalación de plantas de celulosa.

Las formas en que se identifican y visualizan los habitantes de una población del interior del país, como parte de una comunidad específica, responden a diversas operaciones, actos, gestos y dinámicas que no siempre son evidenciadas o planteadas explícitamente.

En la vida cotidiana los sujetos buscamos hacer parte de algo, una o varias formas de identificarnos, de mirarnos y de decirnos, de participar en lo global. Esas formas de identificación cada vez están más vinculadas a prácticas visuales que, además de tener un territorio específico, están atravesadas en muchos casos por lo virtual. "Hoy imaginamos lo que significa ser sujetos no solo desde la cultura en que nacimos, sino desde una enorme variedad de repertorios simbólicos y modelos de comportamiento" (GARCÍA CANCLINI, 2004, p. 161).

Las acciones desarrolladas tienen como objetivo hacer viable los proyectos de vida de las familias rurales en relación al trabajo sin embargo se percibe que prima lo que sostienen Jurado e Tobasura (2012, p. 63): “[...] aunque el ámbito rural tiende a ser bien valorado como espacio de vida, las expectativas laborales 
y familiares y la identidad de los sujetos jóvenes parece construirse sobre el imaginario de la ciudad".

En el Uruguay actual el acceso a conexión a internet y a las redes sociales virtuales hacen que las personas, independientemente de su lugar de residencia, puedan estar simultáneamente en diversos lugares y acceder con un solo click a imágenes y eventos de cualquier sitio. Esta movilidad afecta por completo la forma en que se ve, imagina e interpreta la cotidianidad, impactando también en los habitantes de las zonas rurales. Al mismo tiempo, la creación del Plan Ceibal en 2007 se propuso como objetivo central generar las condiciones para integrar socialmente a partir de la inclusión digital de los escolares. Desde su implementación, este plan ha buscado instrumentar diversas acciones que involucran la formación de docentes así como la conformación de abordajes digitales que se distancian - en muchos casos - de los mecanismos pedagógicos y didácticos vigentes en las escuelas. Como es de suponer, la presencia abrumadora de los dispositivos digitales en nuestros cotidianos genera un protagonismo omnipresente de las imágenes dentro y fuera de las aulas.

Pensar entonces los Estudios de Cultura Visual en el marco de las instituciones escolares constituye una acción fundamental que nos permite volver a orientar, a enfocar, el abordaje pedagógico en relación a la educación artística. Entender el espacio privilegiado que las imágenes ocupan en nuestros lugares cotidianos contemporáneos es condición fundamental para dar sentido a la educación vinculada a las artes visuales, donde las producciones provenientes del mundo del arte constituyen una parte fundamental pero minoritaria dentro de los imaginarios visuales que rodean la existencia de niños y niñas.

Imágenes que, a través de diversos soportes y formas de mostrar, representan diferentes estructuras jerárquicas, de organizar el poder, ideológicas y estéticas que conducen a otras tantas aproximaciones diversas para poder comprender la forma en que la realidad se conforma a nuestro alrededor y esto incide en la vida cotidiana de las personas.

Y del mismo modo, es posible impulsar la producción de imágenes que puedan generar una posibilidad de narrativa acerca de las significaciones vitales de los niños y las niñas de las escuelas, sedimentando la idea de que:

Enseñar un currículum de este tipo ofrece a los alumnos una introducción a las características y los contextos de las imágenes y de los objetos realizados 
por y para diversos grupos de personas, críticas analíticas del poder de las imágenes y los significados de las imágenes visuales, y una oportunidad para producir una contribución de los propios alumnos a la cultura visual. (FREEDMAN, 2006, p. 166).

En este sentido, todo lo que las imágenes intentan transmitir, lo que las imágenes nos dicen y generan, trascienden la idea de una objetividad pre-establecida que el contenido visual debería generarnos y avanzan hacia una noción que necesariamente debe conectarse con las maneras en nos vinculamos con ellas desde la complejidad y necesaria transformación de significado que debemos intentar generar, a partir de poder problematizar de manera crítica su origen y circulación. Lo que las imágenes aparentan visualmente no da cuenta necesariamente del entramado de discursos que las generan ni sobre los que las mismas imágenes actúan a la vez.

En este marco, la cultura visual constituye una plataforma propicia para que, a partir de las imágenes con las que nos vinculamos, se hagan evidentes las construcciones de sentido que se generan sobre nuestras vidas.

De esta manera podemos identificar diferentes niveles de importancia para pensar los espacios escolares a través del vínculo entre la educación artística y la cultura visual: el lugar que ocupan las imágenes como formas de construcción de discurso, más allá de su superficie objetiva visible. En una segunda mirada, podríamos colocar la atención en las trayectorias específicas y las biografías de niños y niñas que se vinculan directamente con imágenes que están a nuestro alrededor y en las que maestros y maestras pueden revisar y colocar en el eje de atención para permitir que emerjan vínculos y relaciones. De alguna manera, esto se trata de intentar trascender la idea de que las imágenes sólo pueden ser vistas y analizadas desde una única perspectiva y avanzar hacia una noción que permita ir hacia la experiencia del espectador en relación a la imagen, y que eso sea lo importante. Trabajar desde la cultura visual en relación a la educación artística tendrá en consideración que los individuos que miran poseen sus propias condiciones de vida, sus trayectorias, experiencias, itinerarios de formación, sus construcciones simbólicas y, por lo tanto, tendrán unas condiciones concretas y situadas de visualización, no homogéneas ni reduccionistas.

Las posibilidades de conformación de las identidades contemporáneas, tanto las individuales como las colectivas tiene un vínculo estrecho con las maneras en 
que los sujetos construyen las imágenes, pero al que también construyen de forma permanente con referencias de todo tipo, principalmente, y ya también de carácter sensible e ideológico y relacionado con varios aspectos de nuestra vida cotidiana.

Otro aspecto a tener en cuenta desde esta perspectiva es la posibilidad de colocar el foco en los artefactos y tecnologías que conducen, soportan o hacen posible la producción y ocurrencia de las imágenes con las que niñas y niños se relacionan. Como señalamos anteriormente, en nuestros contextos las tecnologías de la información y la comunicación vienen a hacer cada vez más complejos los procesos vinculados a la producción, distribución, circulación, y consumo social e individual de las imágenes. A esto deberíamos agregar el impacto que ha tenido la pandemia en nuestra vida diaria y en particular en nuestras relaciones y vínculos interpersonales. A la situación prácticamente normalizada y presente en nuestros cotidianos a través de la cual todos podemos producir y circular nuestras imágenes, se han sumado los procesos de hibridación de lenguajes que el arte no habría reconocido en épocas anteriores, generando procesos de apropiación y resignificación. Hoy, nuestras sociedades acceden muy fácilmente a dispositivos que permiten nuevas circulaciones de imágenes. La pregunta que debemos hacernos es respecto a las formas en que esas imágenes llegan a nosotros, qué discursos nos proponen y de qué manera nos vinculamos con ellas. Las posibilidades de uso y el acceso a niveles de tecnología cada vez más complejos trasciende las pertenencias sociales y cruza cualquier forma de estratificación social que pudiéramos ensayar, aunque exista y permanezca una desigualdad social marcada por la falta de acceso a derechos básicos. La informática, la telefonía celular, la televisión, y la multiplicación de los sistemas de control y transacción a través de infinidad de pantallas con las que las personas nos relacionamos todos los días, nos enfrenta a un flujo de imágenes visuales inédito en la historia de la humanidad. Este hecho otorga un elemento distintivo a nuestra época que desregula los parámetros de tiempo y espacio de los sujetos permitiéndoles "estar presente" en varios sitios a la vez más allá de una idea de materialidad cada vez menos importante; visualizar la misma imagen simultáneamente con otras y otros conocidos o no, en localizaciones diversas; establecer diversas comunicaciones desde identidades o lugares sociales diferentes; inciden en las formas de visualidad de nuestra contemporaneidad. A partir de este enfoque se presenta una perspectiva que nos provoca e involucra directamente como profesores y es la impostergable necesidad de pensar unas 
transformaciones curriculares en nuestras escuelas que permitan incorporar la educación artística a las escuelas con un compromiso real y efectivamente habiliten maneras reflexivas, conceptuales y de prácticas de creación que colaboren a que los sujetos de la educación encuentren allí un espacio de transformación y crítica respecto a los signos de época y a sus propias condiciones de vida. Tal y como sostiene Fernando Hernández (2006, s.p.), una alfabetización para la cultura visual "explora cómo los discursos sociales mediados por imágenes, las artes visuales y las prácticas escolares construyen narrativas acerca del mundo social y contribuye a crear representaciones del mundo y de sí mismo". Las características y condiciones de producción son de un análisis impostergable, especialmente cuando se trata de referencias a la visualidad de época, a las imágenes circundantes que se materializan en las individualidades de cada miembro de los colectivos de la sociedad.

\section{RURALIDADES IMAGINADAS. UNA PROPUESTA DE TRABAJO}

Para relevar y reflexionar sobre las imágenes y los imaginarios artísticos y visuales que circulan en las prácticas y las dinámicas cotidianas de la ruralidad del departamento de Paysandú como formas de pensarse y nombrarse pensamos una propuesta que, desde la mirada interdisciplinaria de la cultura visual. El objetivo inicial es conocer con mayor profundidad las diferentes expresiones y dinámicas de la identidad rural. Preguntarnos ¿Cuál es la significación que la escuela rural tiene para niñas y niños?; ¿qué representaciones visuales hacen éstos de nociones como rural o escolar?; ¿qué elementos y objetos representan la escuela fuera de ésta, en la casa, en el pueblo?; ¿cómo se construye una narrativa visual que dé cuenta de estas representaciones? Estas son algunas de las preguntas que se pueden formular al momento de pensar este dispositivo.

En todos los casos, centrando la atención en sus repertorios simbólicos y generar insumos que contribuyan a la reflexión sobre el habitar el territorio trascendiendo el aspecto productivo.

La iniciativa está pensada para ser llevada adelante conformando grupos con niños de escuelas rurales unidocentes y multigrado de diferentes localidades de Paysandú, proponiendo la realización de al menos cuatro encuentros con niñas y niños, de tres horas cada uno y con reuniones que permitan la interacción con la maestra/maestro a cargo de cada uno de los grupos, durante el intervalo previsto entre cada uno de los encuentros. 
¿Por qué se enmarca la propuesta en las escuelas rurales, unidocentes y multigrado?

Los motivos son varios y contribuyen a definir la escuela rural como ámbito de referencia cultural para los niños y niñas e incluso para sus familias. Carro, Pereira y Santos (2007, p. 2) aportan fundamentos en éste sentido: "La escuela rural en nuestro medio es una institución polivalente; representa al estado en todos los rincones del país. Es también un promotor de las redes sociales, del fortalecimiento de las familias rurales y la revalorización de la identidad local".

Asimismo, en una entrevista en el periódico "La Diaria" de Montevideo, el 18 de enero de 2020 el director del Departamento de Educación para el Medio Rural, del Consejo de Educación Inicial y Primaria (CEIP), Limber Santos (ÁLVAREZ, 2020, p. 4) resaltó que la escuela rural: “[...] sigue siendo la institución pública de mayor penetración territorial; no hay lugar del territorio donde uno pueda desembarcar y que no haya una escuela relativamente cerca, hay una densidad de escuelas muy grande".

En este marco, es posible considerar a la institución escuela rural como espacio pertinente para el desarrollo de esta propuesta, en el entendido de que constituye un espacio donde confluyen miradas estrictamente locales y situadas, y con una perspectiva legítima en torno a las construcciones identitarias vinculadas con lo rural.

De acuerdo a datos del Consejo de Educación Inicial y Primaria (CEIP) en la jurisdicción del departamento de Paysandú hay 58 escuelas rurales, 36 de ellas unidocentes y 22 pluridocentes. En total concurren 1.116 niños a escuelas rurales y trabajan 105 maestros.

\section{DISEÑO FLEXIBLE Y PERSPECTIVA ETNOGRÁFICA}

Para intentar cumplir el objetivo de indagación de este proceso se establece un diseño flexible cualitativo (PIOVANI, 2007) y una perspectiva etnográfica combinando la utilización de técnicas complementarias y herramientas de investigación clásicas y experimentales a modo de laboratorio atendiendo al abordaje interdisciplinario de la propuesta. En este sentido coincidimos en cuanto a que: "Consecuentemente, las metodologías de la cultura visual son híbridas, diversificadas, pudiendo utilizar elementos prácticos y empíricos tanto cuanto abordajes teóricos y creativos" (MARTINS, TOURINHO, 2015, p. 22). Se propone un relevamiento bibliográfico, que permita construir un estado del arte, a partir de una 
matriz de autores y conceptos, conjugados con la experimentación directa.

Las técnicas previstas son observación participante y no participante (realizando un diario de campo, con registro sistemático de observaciones, percepciones, ideas, conceptos, fotografías del espacio para transformarlo en datos primarios recogidos de forma directa). Otra herramienta posible a ser utilizada es la realización de derivas con documentación fotográfica. De esta manera, se pueden generar instancias que habiliten acercarse, sorprenderse para comprender e interpretar estos fenómenos, configurando una etnografía densa que permita rescatar los matices de lo rural.

La disponibilidad de fuentes está controlada, utilizando como primarias la producción de fotografías, collage a cargo del equipo de trabajo y secundarias imágenes fotográficas de archivo, públicos y privados, prensa, mapas disponibles en relación a la pequeña población rural concreta en la que se inserta la institución y a la escuela rural unidocente en particular. El desafío metodológico es que junto a las niñas, niños y maestros se pueda concretar la realización y construcción de un relato visual rural que permita analizar, investigar y reflexionar y evidenciar convergencias y divergencias de las formas de habitar en el territorio. El mismo se construirá con: a) imágenes fotográficas de archivo, b) producción fotográfica propia y c) dibujos, mapas, cartografías.

A partir de esta primera etapa de investigación basada en identificación, selección y sistematización de imágenes y construido este repertorio visual, nos proponemos un análisis intentando visualizar e interpretar habitares urbanos y rurales, con foco en espacios públicos como constructores de identidades, posicionándonos estratégicamente desde la Cultura Visual. Las diferentes y sucesivas etapas de encuentro con los participantes están planteadas como usinas de insumos, prestando especial atención a recuperar un repertorio de imágenes, objetos y relatos que den cuenta de los repertorios visuales que definen la identidad local, así como la forma de ser y estar en el territorio específico.

Los encuentros previstos comienzan con la presentación de la propuesta inicial de trabajo y la autopresentación de los participantes. Luego se plantea la invitación a los niños, niñas y maestro o maestra a cargo a presentar oralmente al equipo docente (foráneo) los espacios de su localidad que consideren más representativos de la identidad y las diferencias que esos espacios tienen con su conocimiento real o supuesto de ciudad. 
Se llevará a cabo un registro de las palabras con las que describen los espacios (función, características, colores, tamaño, anécdotas, materiales, nombres etc.).

A partir de la identificación de esos espacios y de los conceptos se preparará la siguiente instancia de encuentro para focalizar en los lugares más significativos.

Al planificar las actividades y las consignas para los sucesivos encuentros, inevitablemente emergen subtemas como la conexión de los escolares con el espacio público de la localidad que habitan, el reconocimiento del paisaje y de los sitios representativos y los recorridos habituales.

El proceso incluye articular con el grupo de escolares, su docente y los familiares que tengan disponibilidad un recorrido (derivas) por los sitios referenciados y la realización de un registro fotográfico de los espacios y situaciones. Asimismo, se trabajará en la representación de un plano de la localidad, marcando el recorrido y los sitios en los que se realicen paradas. Durante la recorrida se llevará un registro de la mención de los sitios especiales, referencias de construcciones o elementos vegetales que sean indicados por los anfitriones y que ellos consideren que las diferencian de otras comunidades o los representan fuera de la misma.

Una vez completado el proceso se realizarán entrevistas a la maestra y otros participantes sobre la experiencia desarrollada.

Como cierre del proceso de investigación y a partir de una construcción colectiva y colaborativa se proyecta una intervención, a través de un lenguaje artístico, en el paisaje con la intención de apelación, interpelación y diálogo con y entre la comunidad.

\section{UN CAMINO POR RECORRER}

Es en el análisis del proceso participativo que se aspira a lograr que la resignificación de las imágenes y los discursos habituales y naturalizados en relación a la ruralidad y contrapuestas a lo urbano activen la producción de sentidos y discursos identitarios propios que permitan alcanzar los objetivos del proyecto. Las imágenes serán consideradas "[...] en su riqueza contextual, como parte de un discurso social que implica su influencia en la vida social. Los límites se establecen no por la extensión del campo (a todas luces inabarcable) sino por las estrategias de elección, los procedimientos de interpretación a la hora de dirigir la investigación en torno a ellos" (HERNÁNDEZ, 2006, p. 96). 
Visualizar con mayor claridad la contribución social del proyecto en términos educativos y construcción de conocimiento novedoso en un entorno en el que hay relativamente pocos antecedentes.

Asimismo, resulta muy valiosa la incorporación de una documentación detallada de los procesos en el sentido fundamentado por Hernández y Anguita (2012, p. 32): “la documentación como actividad de observación, interpretación y narración de los procesos y experiencias de la infancia con la finalidad de comprender lo que hacemos (niños, docentes y familias) y dar sentido así a nuestras elecciones y tomas de postura. Desde este punto de vista, documentar implica una reflexión sobre el porqué de lo que hacemos, al tiempo que narramos públicamente nuestra tarea educativa y nuestro rol como docentes".

Nuestras sociedades se encuentran hoy ante grandes desafíos, uno de ellos es la necesidad de defender a la escuela pública como ámbitos legítimos de construcción de ciudadanía. Para esto será necesario revisar las propuestas metodológicas, nuestras prácticas docentes y nuestras perspectivas de referencias, para enfocarnos en los sujetos y sus vínculos con sus entornos y construir desde allí un espacio de reflexión que permita discutir y pensar las imágenes desde la posibilidad de construir y reconstruir nuestros propios imaginarios.

\section{REFERÊNCIAS}

ÁLVAREZ, C. Unas 300 escuelas rurales tienen menos de cinco niños; la situación preocupa al director de Educación Rural del CEIP. La Diaria Educación, 18 enero 2020. Disponible en: https://educacion.ladiaria.com.uy/articulo/2020/1/unas-300-escuelas-rurales-tienenmenos-de-cinco-ninos-la-situacion-preocupa-al-director-de-educacion-rural-del-ceip/. Acceso el: 6 marzo 2020.

CARRO, S.; PEREIRA, I.; SANTOS, L. El valor de la educación rural: reflexiones sobre una experiencia de desarrollo. Facultad de Psicología, 2007. Disponible en: de https://psico. edu.uy/sites/default/files/cursos/ps-educacional_el-valor.pdf. Acceso el: 6 marzo 2020.

FREEDMAN, F. Enseñar la cultura visual. Currículum, estética y la vida social del arte. Barcelona: Octaedro, 2006.

GARCÍA CANCLINI, N. Diferentes, desiguales y desconectados. Barcelona: Gedisa, 2004.

HERNÁNDEZ, F. From Visual Literacy to Visual Culture Literacy. En: INTERNATIONAL INSEA 
CONGRESS: Interdisciplinary Dialogues in Arts Education. 1-5 Marso, 2006, Viseu, Portugal. [Comunicación presentada]. Anales [...].Viseu, Portugal, 2006.

Proceedings of International InSEA Congress 2006 Interdisciplinary Dialogues in Arts Education, 1-5 March, Viseu, Portugal.

HERNÁNDEZ, F. Los Estudios de Cultura Visual. La construcción permanente de un campo no disciplinar. Revista La Puerta FBA, [s.I.], n. 2, p. 89-99, 2006.

HERNÁNDEZ, F.; ANGUITA, M. ¿Cómo nos hemos relacionado con las imágenes? Documentar un proceso de relación pedagógica entre un grupo de estudiantes de la universidad y un grupo de niños y niñas de 5 años. Pátio - Revista Pedagógica, Porto Alegre, [s.n.], p. 30-5, 2012. ISSN: 1518-305X

JURADO, C.; TOBASURA, I. Dilema de la juventud en territorios rurales de Colombia: ¿campo o ciudad? Revista Latinoamericana de Ciencias Sociales, Niñez y Juventud, [s.I.], v. 10, n. 1, p. 63-77. 2002.

MARTINS, R.; TOURINHO, I. Educação da cultura visual: aprender, pesquisar, ensinar. Santa Maria, RS: UFSM, 2015.

PIOVANI, J. El diseño de la investigación. En: MARRADI, A; ARCHENTI, N; PIOVANI, J. (Compiladores). Metodologías de las ciencias sociales. Buenos Aires: Emecé Editores, 2007. p. 71-85.

\section{Sobre os autores:}

Gonzalo Vicci: Doctorado de Artes Visuales y Educaciòn, Un Enfoque Construccionista, Universidad de Barcelona. Licenciatura en Artes- Artes Plásticas y Visuales, Instituto Escuela Nacional de Bellas Artes (UDeLaR). E-mail: gonzalovicci@gmail.com, Orcid: https://orcid.org/0000-0003-0498-1646

Mónica Cabrera: Licenciada en Comuniación, Universidad de la República. Docente de la Unidad Académica de Estudios y Prácticas de Cultura Visual, Facultad de Artes, Universidad de la República, Uruguay. E-mail: mcabreragallo@gmail.com, Orcid: https://orcid.org/0000-0003-0484-1758

\section{Recibido en: 11/09/2021 Aprobado en: 13/09/2021}

